\title{
The necessity of establishing a strategic fit between consumer demand and supply chain
}

\author{
Adeel Ashfaq ${ }^{1}$ Miss. Nain Tara Sarfaraz Raja ${ }^{2}$ \\ ${ }^{I}$ (Management Sciences, Foundation University Institute of Engineering \& Management Sciences, Pakistan) \\ ${ }_{2}^{2}$ (Faculty Management Sciences, Foundation University Institute of Engineering \& Management Sciences,
} Pakistan)

\begin{abstract}
The paper's main objective is to analyze the relationship of integration of supply chain functions and customer satisfaction. The paper also focuses on the importance of strategic fit of supply chain in the Pakistan's environment. This kind of research has not been done in Pakistani market. In today's consumer products environment, consumers rule over the market. If they do not find a product from one store, they will buy it from another mall or internet at their desirable price. The explosion of consumer demand has created the complexity and increased cost into the supply chain. Data collected through questionnaire suggested that most of the big stores had the capability to manage demand forecast in time through their supply chains thus bringing customer satisfaction.
\end{abstract}

Keywords - supply chain, consumer demand, price

\section{Introduction}

In the recent years, research on supply chain management and its different dimensions has become subject of high interest (Saunders, 1995, 1998; Christopher, 2001 and Boyle, 2006). At some places in literature, supply chain management has been considered as a basic unit of competitive analysis. Companies, in the modern business world, do not aim at achieving low cost or to improve profit at the cost of partners in the supply chain but to develop supply chain as a source of achieving competitive advantage. In other words, it can be said that it is the supply chain not the firms that compete in the market. This has become the principle of the management of supply chain. The concept of supply chain management has attained high level importance since 1980s. However, this concept has not been described as it is needed. It has been emphasized by many authors that framework and definition of supply chain must be described in a clear way (Babbar and Prasad, 1998; and Ming, 2005). On the other hand, researchers like Saunders (1995) have warned that implementation of a universal definition of supply chain management may result in conflicts and frustration in the management. Moreover, researchers have also laid importance on the need of integration of supply chain for getting a competitive advantage. Under supply chain management, concept of demand integration is discussed in this paper. This paper has focused to discuss the necessity of strategic fit between consumer demand and supply chain.

\section{Originality of research}

This particular research is the original and has not been submitted to any other record ever before. All the sources of data used for this research are acknowledged and authentic. The researcher has put his honest efforts in composing the original work.

\subsection{Objectives}

Following are the objectives of the study:

- To understand the relationship of supply chains and consumer demand through existing literature

- To analyze the relationship of integration of supply chain functions and customer satisfaction

- To discover the advantages of such strategic fit for supermarkets of Pakistan

2.2 Research Problem Statement

In consumer markets, supermarkets are of great importance. These supermarkets have huge consumer traffic. Consumer demand of several products varies with many factors. If supermarkets establish integrate their supply networks with the consumer demand, consumer demand can be satisfied effectively. In this way, studying relationship between supply chain strategic fit and consumer demand is important for achieving customer satisfaction. 


\section{Literature Review}

In today's consumer products environment, consumers rule over the market. If they do not find a product from one store, they will buy it from another mall or internet at their desirable price. The explosion of consumer demand has created the complexity and increased cost into the supply chain. Therefore, retailers and consumer partners need to put more money into the supply chain for its coherent integration to meet the consumer demand (Ming, 2005). Before supplying the product, suppliers have the responsibility to estimate the quantity of production and wholesale price through the prediction of market trends. At the same time, optimal order quantity has been determined by the retailers after estimation of demand. Ming (2005) has asserted that if consumer demand is incorporated into the decisions of supply chain, its final cost can be reduced. However, he also suggests that today's manufacturing is facing challenges to be effective as well as efficient for attaining consumer satisfaction. Bard (2001) suggests that information is highly available through customer relationship marketing, e marketing and supply chain management for making it efficient and effective with the consumer demand. He also suggests that too rigid approach to supply chain management can pose risk to customer satisfaction.

The model for the development of supply chain networks in relation to the competitive needs has also identified the need for the implementation of collaborative, cooperative and competitive practices and relationships in company's supply chains. Christopher (2005) has argued that consumer demand may have long lasting and direct influence on the strategies of the business. This is because the predictable demand and supply can provide alignment in the strategies of the organization and supply chain management. However, uncertain demand and supply in the market may not lead to the responsiveness in the supply chain. Several authors have suggested that companies must assure that their supply chain capabilities must support their abilities for satisfying the demand of a particular consumer segment (Cousins, 2005; Mitra and Bhardwaj, 2010). Many authors have also argued that strategic fit is a concern of compatibility between the supply chain and demand for the satisfaction of consumer demands (Vachon et al, 2009; Cox, 2004; Cox et al, 2007). Therefore, resources in the supply chain need to be developed in integration for establishing strategic alignment in the supply chain of the organization. A company may lead to failure if its strategic values are misaligned in the supply china of the organization and also because of poor management of the organization. Fisher (1997) has suggested that the appropriate procedure for the management of supply chain is to devise a single strategy that must contain the attributes of the demands of consumers. The products demanded can be innovative of functional. the functional products are those products which have predictable and long demand cycles. These products are directed by efficient processes and have lean supply chain management process. Innovative products are those products that have demand which is less predictable and short life cycle need to have flexible supply chains. This flexibility incorporates in their volumes, product mix and delivery (Van de Vaart and Van, 2006).

Researchers have suggested that companies need to incorporate factors like efficiency which refers to the ability of organizations to produce in a lean way by the consumption of fewer resources. Companies must also incorporate responsiveness in the strategy which is the ability of organizations to respond to movements and trends of the market (Vachon et al, 2009). Moreover, they should also operate with superior resources such as flexibility, reliability and speed for responding to market movements in a quick way. Researchers have suggested that market needs drive the supply chains of organization. Moreover, they have also emphasized that supply chains must be formatted and managed by a single strategy that has extreme efficiency and responsiveness (Christopher, 2005 and Chopra and Meindl, 2003). In this way, organizations have the ability to achieve alignment in strategy for achieving the satisfaction of consumer demands. Chopra and Meindl (2003) have also suggested that extension in the scope of strategic fit in the supply chain is the procedure that may lead the organizations to achieve competitive advantage.

Strategic alignment between the supply chain and consumer demand and supply chain can be attained through a quick procedure; rather it is a gradual process (Lee, 2004). Strategic alignment in the supply chain starts when there is alignment between production planning and demand forecasts. After this step, the process intensifies when the alignment needs to be made to the definition and responsibilities and roles of partners in the supply chain. The last step in the alignment of supply chain is the attributes which must be there for maximizing the returns favorable for maximizing the performance of the overall supply chain.

The strategic fit in the supply chain management in the business is important for the success of the organization (Chopra and Meindl, 2007). Many researchers have suggested that proper alignment of supply chain and corporate strategies can lead to competitive advantage for the company (Cox, 2004; Mitra and Bhardwaj, 2010). For the organizations, supply chain strategy and competitive strategy must be aligned (Cox, 2004; Cox et al, 2007; Chopra and Meindl, 2007). Competitive strategy refers to the combination of needs of the organization that must be used for the satisfaction of consumer needs by products and services. On the other side, supply chain strategy refers to the factors that determine purchasing, logistics and manufacturing. Corporate and supply chain strategies need to have similar goals for having a strategic fit (Chopra and Meindl, 2007). 
Jussi (2002) has suggested that companies can achieve competitive advantage by breaking the chain of the traditional manufacturing planning. In traditional manufacturing planning, long lead times are required for resolving conflicts between several activities. In the same manner, long lead times are required for forecasting demand of consumers. The drawback of such planning is that long lead time can decrease the accuracy of demand forecast. Errors in the forecasting planning, increase inventory levels and need of large safety stocks to avoid stock outs. Errors in demand forecasting suggest increasing lead times and unscheduled operatories in the production process which in turn lead to inefficiency of the whole process (Cox et al, 2007). This results in expansion of planning loop, increasing cost, increasing delays and creation of inefficiency in processes.

Holmström $(1994,1995)$ has studied the speed and efficiency in the operations of the organization. His studies have investigated a positive relationship between speed, efficiency and manufacturing department of the organization. he has also found that speedy operations assist the companies to expose and get rid of uncertain operations. His findings suggest that the main source of inefficient and slow operations is distortion in the communication process of the companies. On the basis of the findings, he suggests that organizations need to reduce their inventory commitments to a level where deformation in the consumer demand are minimized. Moreover, this leads to harmony in the production and consumer demand for improving efficiency of organizational processes.

In the existing literature, relationships between operational speed and efficiency and time based management are discussed as important issues for creating integration in the supply chain (Stalk, 1988 and Womack et al., 1991). The researchers have elaborated that in the manufacturing industry, need of competitive advantage has become very high. Womack and Jones (1996) have elaborated that the Japanese manufacturing industry has taken the competitive advantage, all over the world, because of lean thinking which evolved from flexible manufacturing and scale based strategy. This can be suggested as an example of the time based source of competitive advantage (Womack and Jones, 1996).

Here the case of customer satisfaction has been elaborated in the context of alignment in the strategy between supply chain and consumer demand. Through the study of literature review regarding strategic fit between supply chain and demand, this study has aimed at exploring the strategic fit between supply chain and consumer demand. Several studies have suggested that competition based on time in the manufacturing industries has resulted in the establishment of collaboration among suppliers (Hines, 1998; Zirpoli and Caputo, 2002 and Choi and Wu, 2009). It has been suggested by Pfohl and Gareis (2005) that establishing parks of suppliers, who have geographical nearness to the manufacturers, enhance the synchronization in the logistics process. They also suggested that such synchronization may lead to a reduction in cost.

In the every industry, different types of suppliers and customers exist who are stepping up their relations. In some cases, such an alignment is totally directed to the dedication to customers. One reason for alignment between suppliers and manufacturers may be the supply decisions of manufacturers focused on the strategy of single sourcing for a particular item, with interest in large consolidated volumes for ensuring coordination between several activities performed during the process of manufacturing (Gadde and Hakannsson, 2001). The second argument may be to form supplier belts at the time when companies are directed to establish subsidiaries or to move at a particular geographical location proximate to the manufacturers' manufacturing unit (Correa, 2001). The aim in these cases is coincidental which is to create situation of circumstances that may lead to integration in the activities of suppliers and manufacturers in the processes of logistics and operations process which may lead to a higher level of service delivered to customers.

In real terms, the concept of supply chain management has extended from the ideas of business unit operations to the supply chain. Coordinating different activities of the supply chain from attaining raw materials to delivery of finished goods to the consumers is the supply chain management. Supply chain management does not refer to the local optimization of specific business units rather improvement in the efficiency of the whole process. Many researchers have suggested that the effective performance in the organization can be achieved through consolidation of customers and supplier bases, speeding the exchange of information and flow of materials, removing bottlenecks from the supply chain and establishing long lasting relations between suppliers and customers to influence the capabilities of companies involved in the supply chain (Yoshino, 1995; Lambert, 1996 and Jussi, 2002).

Strategic links between the suppliers are crucial to ensure the strategic alignment in the supply chain and consumer demand. Chopra and Meindl (2007) have suggested that strong links between the suppliers lead to high strategic fit between supply chain and consumer demand. Higher level of strategic fit exists in situations when direct suppliers and manufacturers have very strong link with each other. This also creates a dependency between suppliers and manufacturers (Barbieri and Mahapatra, 2009). In close relationships, manufacturers and suppliers coordinate with each other and several activities leading to higher strategic fit in supply chain and demand. In this regard, maintenance of relationships with the consumers and suppliers is important for the organizations for getting competitive advantage by maintaining a strategic fit between supply chain and consumer demands. 


\section{Study Design}

The study design of this particular research is a case study of supermarkets in Pakistan. Through case studies of supermarkets, strategic fit between supply chain and consumer demand will be evaluated in relation to the consumer satisfaction. This study design is suitable for this research to evaluate its objectives in detail. Theoretical framework of the research is as follows:

Consumer Demand: It can be defined as the number or percentage of customers in a firm who want a particular product (s) for a certain amount of money.

Supply Chain: It refers to the stream of raw materials running from a single point of production to the supply of finished goods to end customers. Supply chain functions may include manufacturing, purchasing, transportation, warehousing, forecasting demand, customer service, and managing supply.

Customer Satisfaction: It can be defined as the state of customers at which the perceived performance of the product or service is equal or above the expected performance.

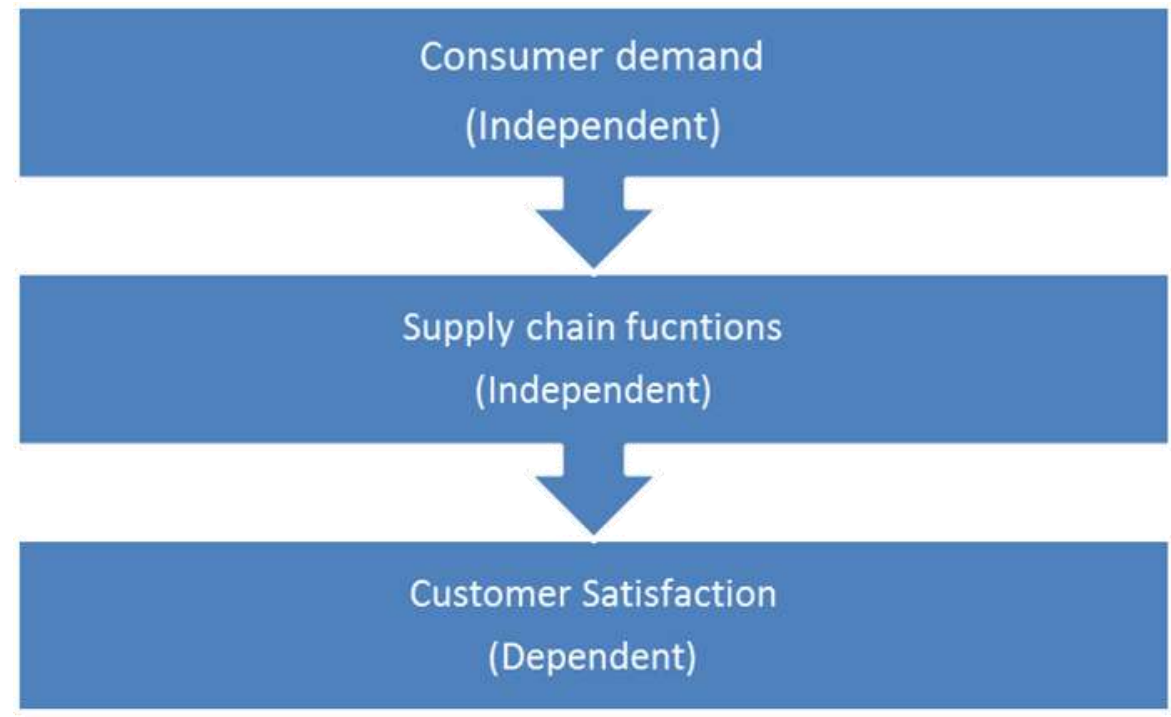

\subsection{Hypothesis:}

On the basis of the above discussion on the literature review, following hypothesis as being derived:

H0: Integration of supply chain and consumer demand does not influence the customer satisfaction

H1: Integration of supply chain and consumer demand influence the customer satisfaction

H0: Integration of supply chain functions has no influence on customer satisfaction.

H1: Integration of supply chain functions has influence on customer satisfaction.

\section{Type of Research}

This particular research is a pragmatic research which includes qualitative and quantitative approaches of data collection. By using qualitative methods, existing literature has been reviewed regarding supply chain and consumer demand. This methodology is adopted to evaluate the first objective of the research. Quantitative methodology has been used to find the need of strategic fit between the supply chain and consumer demand in supermarkets in Pakistan.

\subsection{Type of Data}

Primary and secondary data has been included in this research. Secondary data has been used for composing literature review whereas primary data has been used for evaluating the hypothesis of the research. Primary data from the management respondents of the supermarkets of Pakistan has been used.

\subsection{Data Collection Method}

A survey will be conducted from the management respondents of supermarkets in Pakistan.

\subsection{Sample and Population}

Population of the research consists of supermarkets of Pakistan. A sample of 300 staff members of markets in the Islamabad and Rawalpindi has been selected for this research. The sample has been selected through convenience sampling for conducting survey. The sample has been selected from big supermarkets in 
the twin cities. Moreover, small and medium FMCG stores are also targeted for data collection. Data collected through the survey will be analyzed through descriptive analysis techniques.

\section{Data Analysis}

It was found that in big stores, supply chain of the stores was triggered through forecasts $(67 \%)$ whereas in medium sized and small sized stores, the supply chain functions are triggered through consumer demand $(33 \%)$. For small stores, stock outs were the big problem whereas for big stores, maintaining obsolete inventory was big issue. Regarding management of supply chain, the responses were supply chain (38\%), marketing (17\%), operations (16\%), and procurement (29\%). Regarding integration of supply chains, the score was $23 \%$ extremely integrated, $19 \%$ very integrated, $27 \%$ moderately integrated, somewhat integrated $12 \%$ and not at all integrated $19 \%$. The big stores were having moderately or extremely integrated supply chains. On the other hand, small stores were having somewhat or not at all integration in supply chains. The stores that have highly efficient management of demand of customers have high increase in profitability. The scores in this context were $12 \%$ highly increase, $26 \%$ slightly increase, $32 \%$ slow increase, $19 \%$ does not increase and $11 \%$ not sure. Regarding forecast of demand, the scores were $12 \%$ highly effective, $32 \%$ moderately effective, $29 \%$ slightly increase, $18 \%$ not effective and $9 \%$ not sure.

Regarding management of demand and stock outs, it was found that $63 \%$ stores had the ability to provide alternative items to consumers whereas $37 \%$ stores lacked this capability. In response to the efficiency of staff, $51 \%$ stores had efficient staff to fulfill the customer demand in time. On the other hand, $49 \%$ stores did not have efficient employees to satisfy the needs of the organization in time. Regarding customer satisfaction, the scores were $23 \%$ highly satisfied, $34 \%$ satisfied, $11 \%$ neutral, $21 \%$ dissatisfied, and $11 \%$ strongly dissatisfied.

The responses to the questionnaire suggested that most of the big stores had the capability to manage demand forecast in time through their supply chains. This integration of supply chain functions has worked in the big stores to bring customers satisfaction. On the other hand, small and medium sized stores did not manage their supply chain functions through formal supply chain departments. Moreover, their forecasting techniques were also ineffective which led to lower levels of customer satisfaction

\subsection{SPSS}

\section{Correlations}

\begin{tabular}{|ll|r|r|r|}
\hline & & supplychain & $\begin{array}{c}\text { consumers } \\
\text { atisfaction }\end{array}$ & $\begin{array}{c}\text { consume } \\
\text { rdemand }\end{array}$ \\
\hline supply chain & Pearson Correlation & 1 & $.492^{* *}$ & $.606^{* *}$ \\
& Sig. (2-tailed) & & .001 & .000 \\
& $\mathrm{~N}$ & 200 & 200 & 200 \\
\hline consumersatisfaction & Pearson Correlation & $.492^{* *}$ & 1 & $.926^{* *}$ \\
& Sig. (2-tailed) & .001 & & .000 \\
& $\mathrm{~N}$ & 200 & 200 & 200 \\
\hline consumerdemand & Pearson Correlation & $.606^{* *}$ & $.926^{* *}$ & 1 \\
& Sig. (2-tailed) & .000 & .000 & \\
& $\mathrm{~N}$ & 200 & 200 & 200 \\
\hline
\end{tabular}

**. Correlation is signif icant at the 0.01 level (2-tailed).

Table:

The following table shows that integration of supply chain and consumer demand have positive correlation with the customer satisfaction.

Coefficients

\begin{tabular}{|c|c|c|c|c|c|c|}
\hline \multirow[b]{2}{*}{ Mode } & & \multicolumn{2}{|c|}{$\begin{array}{l}\text { Unstandardized } \\
\text { Coeff icients }\end{array}$} & \multirow{2}{*}{$\begin{array}{c}\text { Standardized } \\
\text { Coeff icients } \\
\text { Beta }\end{array}$} & \multirow[b]{2}{*}{$\mathrm{t}$} & \multirow[b]{2}{*}{ Sig. } \\
\hline & & $B$ & Std. Error & & & \\
\hline \multirow[t]{3}{*}{$\overline{1}$} & (Constant) & 42.168 & 7.117 & & 5.925 & .000 \\
\hline & consumerdemand & .693 & .220 & 1.059 & 3.144 & .003 \\
\hline & consumersatisfaction & -5.699 & 3.928 & -.489 & -1.451 & .155 \\
\hline
\end{tabular}

a. Dependent Variable: supply chain

Application of Barron's and Kenny's Test: 


\section{Communalities}

\begin{tabular}{|l|r|r|}
\hline & Initial & Extraction \\
\hline consumerdemand & 1.000 & .593 \\
supply chaindunctions & 1.000 & .944 \\
consumersatisfaction & 1.000 & .634 \\
\hline
\end{tabular}

Extraction Method: Principal Component Analysis.

Total Variance Explained

\begin{tabular}{|l|r|r|r|r|r|r|}
\hline \multirow{2}{*}{ Component } & \multicolumn{3}{|c|}{ Initial Eigenvalues } & \multicolumn{3}{c|}{ Extraction Sums of Squared Loadings } \\
\cline { 2 - 7 } & Total & \% of Variance & Cumulative \% & Total & \% of Variance & Cumulative \% \\
\hline 1 & 1.166 & 38.855 & 38.855 & 1.166 & 38.855 & 38.855 \\
2 & 1.006 & 33.519 & 72.374 & 1.006 & 33.519 & 72.374 \\
3 & .829 & 27.626 & 100.000 & & & \\
\hline
\end{tabular}

Extraction Method: Principal Component Analy sis.

Component Matri

\begin{tabular}{|l|r|r|}
\hline \multirow{2}{*}{} & \multicolumn{2}{|c|}{ Component } \\
\cline { 2 - 3 } & 1 & \multicolumn{1}{|c|}{2} \\
\hline consumerdemand & .769 & .042 \\
supply chaindunctions & .216 & .947 \\
consumersatisfaction & .726 & -.327 \\
\hline
\end{tabular}

Extraction Method: Principal Component Analysis.

a. 2 components extracted.

The result shows that component value of consumer demand is less than 0.05 , so null hypothesis is rejected. This is same in case of consumer satisfaction.

\section{Conclusion}

On conclusion, it can be said that the size of stores has important role in the effective functioning $f$ supply chain management. The stores which were large in size had the ability to forecast demand in an efficient way. This efficiency in forecasting demand enabled them to meet the demands of customers in time which in turn led to customer satisfaction. On the other hand, lack of inefficient staff, separate supply chain department and ineffective forecasting technique impacted on the ability of staff of middle sized and small sized staff to meet the demand of customers in time. Most of the large stores in the sample had highly integrated supply chains whereas stores which were small did not have any strong idea of supply chain integration. This was the reason that large stores had high customer satisfaction as compared to the small stores. The results have suggested that integration of consumer demand and supply chain functions influence customer satisfaction.

\section{Recommendations}

The stores whether small or large need to have a separate department or areas for managing their supply chain functions. Effective forecasting techniques need to be implemented in the organization because these techniques help the store staff to meet consumer demand and avoid stock outs. Moreover, the stores need to hire efficient employees who have the capability to deal with the customers and finalize deal with them even in case of shortage of products.

\section{References}

[1] Babbar, S., Prasad, S., 1998. International purchasing, inventory management and logistics research: an assessment and agenda. International Journal of Operations and Production Management 18 (1), 636

[2] Barbieri, P. and Mahapatra, S. 2009. Buyer-supplier relationship in supply network: implications of tier-II supplier management practices, Proceedings of the 2009 European Operation Management Association Conference, Götenburg

[3] Chopra, S. and Meindl, P. 2007. Supply Chain Management: Strategy, Planning, and Operation. 3rd Ed., Upper Saddle River, New Jersey: Pearson Education, Inc.

[4] Cox, A.; Chicksand, D. Yang, T. 2007. The proactive alignment of sourcing with marketing and branding strategies: a food service case. Supply Chain Management: An International Journal. Volume: 12 Issue: 5

[5] Correa, L. H. 2001. The VW Resende (Brazil) plant modular consortium SCM model after 5 years of operation, Proceedings of the 2001 Annual Conference of the Production and Operations Management Society, Orlando.

[6] Christopher, M. 2000, The agile supply chain: competing in volatile markets, Industrial Marketing Management, Vol. 29, pp. 37-44

[7] Choi, T. Y. and Wu, Z. 2009. Triads in supply networks: Theorizing buyer-supplier- relationships, Journal of Supply Chain Management, Vol. 45 No. 1, pp. 8-25.

[8] Cox, A. 2004. Business relationship alignment: on the commensurability of value capture and mutuality in buyer and supplier exchange. Supply Chain Management: An International Journal. Volume: 9 Issue: 5 
[9] Cousins, P. 2005. The alignment of appropriate firm and supply strategies for competitive advantage. International Journal of Operations \& Production Management; Vol. 25 Issue 5, p. 403-428

[10] Fisher, M.L. 1997. What is the Right Supply Chain for your Product. Harvard Business Review. Vol. 75, n.2.

[11] Gadde, L.E., Hakansson, H. 2001. Supply Network Strategies. Chichester: John Wiley \& Sons.

[12] Holmström, J., 1994. The relationship between speed and productivity in industry networks: a study of industrial statistics. International Journal of Production Economics 34 (1), 91-98.

[13] Hines, P., Malaika, H., Rich, N., 1998a. Competing against ignorance: advantage through knowledge. International Journal of Physical Distribution and Logistics Management 28(1).

[14] Holmström, J., 1995. Speed and efficiency - a statistical enquiry of manufacturing industries. International Journal of Production Economics 39 (3), 185-191.

[15] Jussi. 2002. From supply to demand chain management: efficiency and customer satisfaction. Journal of Operations Management 20.p 747-767

[16] Lee, H. L. 2004. The Triple-A Supply Chain. Harvard Business Review. Vol 82, n.10.

[17] Lambert, D.M., Emmelhainz, M.A., Gardner, J.T., 1996. So you think you want a partner? Marketing Management 5 (2), $24-33$.

[18] Mitra, A,; Bhardwaj, S. 2010. Alignment of Supply Chain Strategy with Business Strategy. The IUP Journal of Supply Chain Management. Vol. VII, N. 3

[19] Ming, 2005. Supply Chain Coordination with Demand Disruptions under Convex Production Cost Function. Wuhan University Journal of Natural Sciences. Vol. 10 No.3 pp. 493-498

[20] Pfohl, H. C. Gareis, K. 2005. Supplier Parks in the German Automotive Industry. International Journal of Physical Distribution \& Logistics Management. Vol. 35, n. 5.

[21] Qi X, Bard J F, Yu G. 2004. Supply Chain Coordination with Demand Disruptions. Omega,32:301-312.

[22] Stalk, G., 1988. Time: the next strategic advantage. Harvard Business Review 66 (4), 41-51.

[23] Saunders, M.J., 1995. Chains, pipelines, networks and value stream: the role, nature and value of such metaphors in forming perceptions of the task of purchasing and supply management. First Worldwide Research Symposium on Purchasing and Supply Chain Management, Tempe, Arizona, pp. 476 - 485.

[24] Van der Vaart, T.; Van, D. P. 2006. Buyer-focused Operations as a Supply Chain Strategy. International Journal of Operations \& Production Management. Vol. 26, n. 1

[25] Vachon, S., Halley, A. and Beaulieu, M. 2009. Aligning competitive priorities in the supply chain: the role of interactions with suppliers, International Journal of Operations \& Production Management. V. 29 No. 4, pp. 322-344.

[26] Womack, J.P., Jones, D.T., 1996. Lean Thinking: Banish Waste and Create Wealth in Your Corporation. Simon \& Schuster, NY.

[27] Womack, J.P., Jones, D.T., Roos, D., 1991. The Machine that Changed the World: The Story of Lean Production. Harper Perennial, NY.

[28] Yoshino, M., Rangan, S., 1995. Strategic Alliances: An Entrepreneurial Approach to Globalization. Harvard Business School Press, Boston.

[29] Zirpoli, F.; Caputo, M. 2002. The Nature of Buyer-Supplier Relationships in Co-design Activities: The Italian Auto Industry Case. International Journal of Operations \& Production Management. Vol. 22, n. 12.

\section{Appendix: Questionnaire \\ Supply Chain Functions:}

1. What dose supply chain trigger?

- Consumer demand

- Forecast

- Not sure

2. What is most important consumer demand challenge for your organization?

- Long lead times

- Stock outs

- Excess inventory

- Obsolete inventory

3. Which department is responsible for demand management?

- Supply chain

- Marketing

- Operations

- Procurement

4. What is the degree of integration of the supply chain of your organization?

- Extremely integrated

- Very integrated

- Moderately integrated

- Somewhat integrated

- Not at all integrated

5. How effective is the demand forecast of your company?

- Highly effective

- Moderately effective

- Slightly effective

- Not at all effective

- Not sure 


\section{Customer Satisfaction}

6. What is the usual feedback of customers regarding their satisfaction level towards store?

- Highly satisfied

- Satisfied

- Neutral

- Dissatisfied

- Highly dissatisfied

\section{Consumer Demand}

7. The store has ability to provide alternative items to customers?
- Yes

- No

8. The store staff is efficient to fulfill the demand of customers in time?

- Yes

- No

9. What is impact of demand management on profitability of the company?

- Highly increases

- Slightly increases

- Slowly increases

- Does not increase

- Not sure 